\title{
Antimicrobial Use in Commercial Poultry Production Systems in Kiambu County, Kenya: A Cross-Sectional Survey on Knowledge, Attitudes and Practices
}

\author{
James G. Ndukui ${ }^{1,2}{ }^{*}$, Joseph K. Gikunju ${ }^{3}$, Gabriel O. Aboge1, James M. Mbaria ${ }^{1}$ \\ ${ }^{1}$ Department of Public Health, Pharmacology and Toxicology, College of Agriculture and Veterinary Sciences, University of \\ Nairobi, Kenya \\ ${ }^{2}$ Department of Nursing, Catholic University of Eastern Africa, Langata Campus, Nairobi, Kenya \\ ${ }^{3}$ Department of Medical Laboratory Sciences, College of Health Science, Jomo Kenyatta University of Agriculture and Technology, \\ Nairobi, Kenya \\ Email: *ndukuiga@gmail.com, *jndukui@students.uonbi.ac.ke
}

How to cite this paper: Ndukui, J.G., Gikunju, J.K., Aboge, G.O. and Mbaria, J.M. (2021) Antimicrobial Use in Commercial Poultry Production Systems in Kiambu County, Kenya: A Cross-Sectional Survey on Knowledge, Attitudes and Practices. Open Journal of Animal Sciences, 11, 658-681.

https://doi.org/10.4236/ojas.2021.114045

Received: June 22, 2021

Accepted: October 9, 2021

Published: October 12, 2021

Copyright $\odot 2021$ by author(s) and Scientific Research Publishing Inc. This work is licensed under the Creative Commons Attribution International License (CC BY 4.0).

http://creativecommons.org/licenses/by/4.0/ (c) (i) Open Access

\begin{abstract}
Background: Antibiotic resistance is putting the commercial poultry production systems across the globe at risk of losses due to the failure of treatments for animals and human health which has been associated with overuse and misuse of antibiotics in poultry farming. One possible approach to the resistance problem is ensuring adequate knowledge, attitudes, and practices on antimicrobial use by farmers on commercial production systems across the globe are applied. Therefore, the current study was carried out to determine factors that could promote antimicrobial use in commercial poultry production systems of Kiambu County, Kenya. Materials and Methods: A descriptive cross-sectional survey was conducted on commercial poultry production systems of Kiambu County to determine the level of knowledge, attitudes, and practices on antimicrobial use. One hundred and fifty-six $(n=156)$ semistructured questionnaires imprinted in a mobile Open data kit were administered to capture the level of knowledge, attitudes, and practices on antimicrobial usage in commercial poultry production systems of Kiambu County. Results: Out of the 156 commercial poultry farmers who participated in this study, females accounted for $(64 \%)$ with $51 \%$ of them keeping layers between 50 - 500 birds as medium scale farmers. In the study, most of the farmers were 45 years and above (61\%) and they had obtained a secondary level of education (34\%). We further noted that $67 \%$ of the farmers obtain antibiotics through self-prescription/personal experience. Additional lack of veterinary
\end{abstract}


officers (77\%) and consultation services (72\%) was also mentioned as key challenges in poultry production. The majority of the respondents $(63 \%)$, indicated Tetracycline as the most commonly used antibiotic in their farms, with the most preferred subtypes of tetracycline and Amoxicillin being Oxytetracyclines (85\%) and Amoxi (88\%) respectively. Nearness to veterinary services significantly $(\mathrm{P}<0.05)$ contributed to the use of antibiotics agents. Additionally, the area of residence, type of production, number of years in farming, and average number of birds kept also significantly $(\mathrm{P}<0.05)$ influenced the level of knowledge and practice on antimicrobial usage. Conclusion: Generally, the level of knowledge and practice on antibiotic use among commercial poultry farmers in Kiambu County is still lacking. This was witnessed with continued use of antibiotics without a prescription from veterinary/ livestock extension offices, which is inconsistent with the general recommendation on antimicrobial stewardship. Therefore, the current research calls for intervention measures such as extensive education to farmers on the rational use of antimicrobial agents in commercial poultry disease management, observance of withdrawal periods, and the impacts of residues on public health.

\section{Keywords}

Antimicrobial Use, Antimicrobial Resistance, KAPs, Commercial Poultry Production, Multidrug Resistance

\section{Background Information}

The essence of poultry farming in many families in developing countries cannot be overemphasized, as it has become a popular enterprise that contributes enormously to income, food security, and the national economy according to FAO [1] [2]. The demand for poultry and poultry products is on the growing trend due to income growth, urbanization, dietary benefits such as protein, micronutrients and higher poly-unsaturated fatty acids and less cholesterol as stated by FAO [2]. Recently, the government of Kenya earmarked the poultry industry as a strategic intervention sector for realizing one of the big four agendas on food safety and security, and on the millennium goal of alleviating poverty and improvement in nutrition because of its short generation interval, high rate of productivity, less land demanded, low economic value, minimal cultural/ religious taboos, and manure generation which complements crop-livestock subsystems. In addition, technology innovation through the promotion of the commercialization of poultry will in the long run address the increasing demand for poultry and their products, which, in turn, will reduce poverty and improve food security.

Due to increased poultry product demand and the urge for white meat, commercial poultry production systems have been embraced across the country which has resulted in increased demand for antimicrobials. In commercial poultry production systems, antimicrobial agents are used for therapeutic, prophy- 
lactic, and growth promotion purposes and their use has been on the rise in many developing countries according to Geidam et al. [3] and Morley et al. [4]. According to Mellon et al. [5] the Union of Concerned Scientists in the USA, approximated $70 \%$ of total antibiotics in use are for non-therapeutics purposes. Furthermore, according to Cohen [6], 80\% of antibiotics used in poultry production worldwide are unnecessary. This was further cemented by Apata [7] who claimed that this complex approach of antimicrobial use in livestock production between the volumes of antibiotics used and the rate of bacterial resistance development indicates that the more we use them indiscriminately the more we tend to lose them.

\section{Materials and Methods}

\subsection{Study Area}

Kiambu County covers an area of $13,191 \mathrm{~km}^{2}$ and is located to the north of Nairobi and west of Mt. Kenya (Figure 1) and it's estimated to have 4,383,743 inhabitants according to the 2009 population census. The high population growth in this area favors commercial poultry production more than other types of livestock production. This is because Kiambu is predominantly an intensive smallholder production region, but it patterns and extent of antimicrobial use significantly differ from other regions of Kenya. According to the report by Nyaga [8], Kiambu County also has got 5351 (broiler farmers) and 1185 (layer farmers) who are for commercial purposes and 12,633 for dual purpose activities.

\subsection{Study Population}

Commercial poultry farmers reared both broilers and layer birds in selected sub-counties of Kiambu County, Kenya.

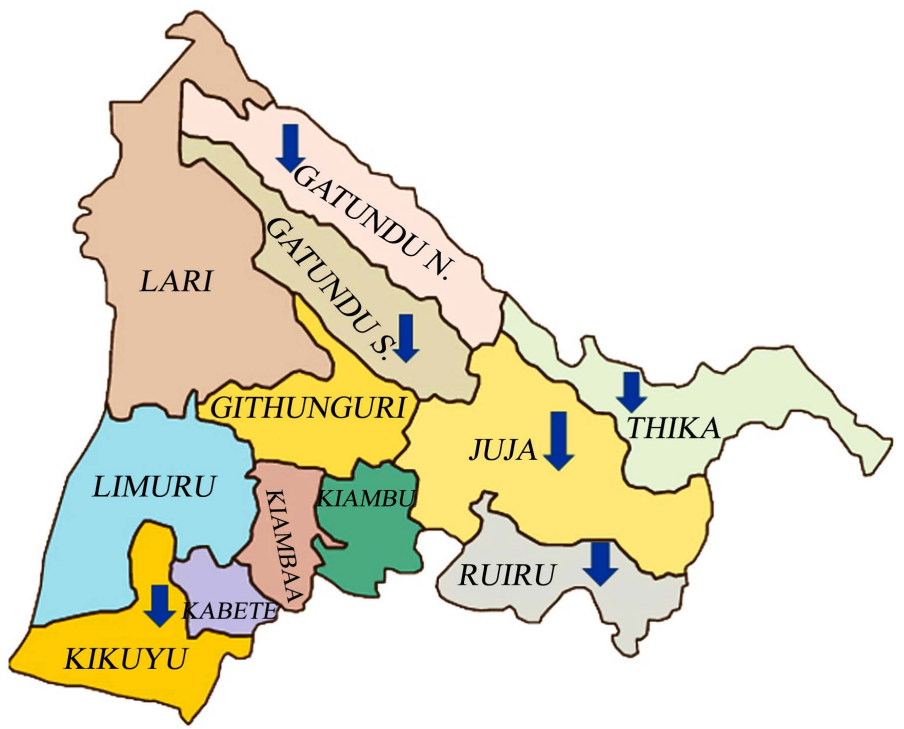

Figure 1. Map of Kiambu County indicating study areas being shown with blue arrow Source: Geomaps Kenya. 


\subsection{Study Design}

A community-based cross-sectional study was employed. A two-stage cluster sampling procedure was used. The sub-counties (the primary sampling unit) were first identified as: Kikuyu; Ruiru; Gatundu North; Gatundu South; Thika and Kiambu and homesteads (the secondary sampling unit) in the selected subcounty were randomly selected. The veterinary extension officers, Community based animal health workers (CBAHW), and village guides were used to give direction and in questionnaire administration to the farms.

\subsection{Questionnaire Administration}

On the predefined field day (November, 2020 to February 2021), the field team explained the project objectives and methods to all inhabitants of the homesteads selected for data collection, and informed consent was sought from all participants individually. Inclusion criterion was any inhabitant of a selected homestead, rearing poultry for commercial production. It was made very clear that inclusion was optional. The formal constructed interviews were conducted using a survey designed with a questionnaire imprinted in a mobile Open data kit, which was used to capture the level of knowledge, attitudes, and practices on antimicrobial usage in commercial poultry production systems of Kiambu County. The questionnaire had both closed and open-ended questions. Each interview varied between approximately $20 \mathrm{~min}$ up to $1 \mathrm{hr}$. Interviewees were informed that their participation was confidential.

\subsection{Data Analysis and Presentation}

Qualitative (Socio-demographic information, knowledge, attitude, practices, and gender) data was analyzed descriptively by ranking responses according to the respondents and presented in the form of tables and graphs. Quantitative data was coded and analyzed using SPSS version 18 statistical software. Comparison between variables was done using Chi square and t-test statistics for the hypotheses as a test of variable independence (occurring due to chance) depending on the data with $\mathrm{P}$-value $<0.05$ considered significant.

\section{Results}

\subsection{Socio-Demographic Characteristics of Commercial Poultry Farmers in Kiambu County, Kenya}

A total of 156 commercial poultry farmers from the six selected sub-counties of Kiambu participated as follows in the study Gatundu North (13\%), Gatundu south (12\%), Juja (13\%, Kikuyu (24\%), Ruiru (21\%) and Thika (17\%). The female accounted for two-third (64\%) of the study participants. Majority of the farmers were aged above 45 years (61\%). In the study sub-counties most of the poultry farmers were married (91\%). Overall, (34\%) of the poultry farmers had attained secondary school education; $22 \%$ diploma education; $18 \%$-primary; $13 \%$ certificate; Degree-10\%; Masters-1\% and 3\%-no formal education re- 
spectively. Majority of the farmers are from the Kikuyu Sub-county (24\%), seconded by Ruiru (21\%) with Gatundu South (12\%) with the least number of poultry farmers. More than half of the farmers were layer farmers (51\%) with the majority having been in poultry farming for more than 5 yrs (44\%). It was also noted that most farmers keep an average number of birds between 50 - 500 (67\%) with layer bird farming being the most preferred type of production (47\%). The study also showed that most farmers prefer keeping both feed (46\%) and income (42\%) records as indicated in Table 1 below.

\subsection{Role Played by Farmers on the Use of Veterinary Antimicrobials in Commercial Poultry Production Systems in Kiambu County}

Table 2 presents results on knowledge, attitudes, and practices on the role played by farmers on the use of veterinary antimicrobial agents in commercial poultry production systems in Kiambu County. Eighty-seven percent of farmers (87\%) indicated that they obtain their antimicrobial drugs through prescription by veterinary officers. However, $67 \%$ of the farmers buy or obtain these drugs although personal experience while $8 \%$ of the farmers obtain antimicrobial agents through their fellow farmers. $86 \%$ of the farmers pointed out that they are able to get advice and follow them (85\%) on how to use this antimicrobial agent from Veterinarians (84\%), Drug shop sellers (57\%), From fellow Farmers (32\%), From CBAHW of the area (21\%), and from others (1\%) successively. It was also noted that $85 \%$ of the farmers are satisfied with the advice they get from the listed personnel and $46 \%, 33 \%$, and $21 \%$ of farmers have to walk medium distance $(3-4 \mathrm{~km})$, short distance $(1-2 \mathrm{~km})$ and long distance (above $5 \mathrm{~km})$ respectively to obtain this veterinary services as indicated in Table 2 below.

Figure 2 presents the results on who does the diagnoses of sick birds in the farms. From the results, both the veterinarian (65\%) and the farmer (65\%) have equal preponderance of carrying the diagnosis of the sick birds from the farms, followed by the community based animal health worker (26\%). The farmworker (5\%) and fellow farmer (3\%) with the least percentage of undertaking diagnosis of the sick birds as indicated in Figure 2 below.

Table 3 presents the results on the level of knowledge on scrutinizing and assessing major challenges facing Kiambu commercial poultry farmers on antibiotic use. $72 \%$, and $49 \%$, indicated that antibiotics are expensive for them to afford, with a lack of money to buy drugs respectively. We also noted that $51 \%$ and $34 \%$ of the farmers lack knowledge on proper use of antibiotics and have challenges of the unfamiliar languages used in the inserts respectively. Lack of specific measuring containers (58\%), lack of veterinary officers (77\%) and consultative services $(72 \%)$ were the key challenges that the farmers faced as shown in Table 3 below.

Table 4 presents the results of the most stocked and preferred type's antimicrobial agents in the management of diarrhea, sudden death, emaciation, and swollen eyes with watery discharge in commercial poultry production systems of 
Table 1. Socio-demographic characteristics of poultry farmers in Kiambu County, Kenya $(\mathrm{n}=156)$.

\begin{tabular}{|c|c|}
\hline Study Variable & Total percentage $(\%), \mathrm{n}=156$ \\
\hline \multicolumn{2}{|l|}{ Gender } \\
\hline Male & $36 \%(56)$ \\
\hline Female & $64 \%(100)$ \\
\hline \multicolumn{2}{|l|}{ Age (Yrs) } \\
\hline $15-25$ & $1 \%(2)$ \\
\hline $26-35$ & $11 \%(17)$ \\
\hline $36-45$ & $27 \%(42)$ \\
\hline$>45$ & $61 \%(95)$ \\
\hline \multicolumn{2}{|l|}{ Marital status } \\
\hline Single & $9 \%(14)$ \\
\hline Married & $91 \%(142)$ \\
\hline Divorced & $0 \%(0)$ \\
\hline \multicolumn{2}{|l|}{ Education level } \\
\hline Primary & $18 \%(28)$ \\
\hline Secondary & $34 \%(53)$ \\
\hline Certificate & $13 \%(20)$ \\
\hline Diploma & $22 \%(35)$ \\
\hline Degree & $10 \%(15)$ \\
\hline Master's degree & $1 \%(1)$ \\
\hline No formal education & $3 \%(4)$ \\
\hline \multicolumn{2}{|l|}{ Region } \\
\hline Gatundu North & $13 \%(20)$ \\
\hline Gatundu south & $12 \%(19)$ \\
\hline Juja & $13 \%(21)$ \\
\hline Kikuyu & $24 \%(37)$ \\
\hline Ruiru & $21 \%(33)$ \\
\hline Thika & $17 \%(26)$ \\
\hline \multicolumn{2}{|l|}{ Designation } \\
\hline Layer farmer & $51 \%(80)$ \\
\hline Broiler farmer & $17 \%(26)$ \\
\hline Multipurpose farmer & $32 \%(50)$ \\
\hline \multicolumn{2}{|c|}{ No of years in poultry farming } \\
\hline Less than $1 \mathrm{yr}$ & $4 \%(6)$ \\
\hline One year & $3 \%(5)$ \\
\hline Two years & $10 \%(16)$ \\
\hline Three years & $16 \%(24)$ \\
\hline Four years & $8 \%(12)$ \\
\hline Five years & $17 \%(26)$ \\
\hline$>5 \mathrm{yrs}$ & $44 \%(67)$ \\
\hline
\end{tabular}




\section{Continued}

Average No. of birds kept

$<50 \quad 1 \%(2)$

$50-500 \quad 67 \%(105)$

$501-1000 \quad 21 \%(33)$

$1001-5000 \quad 10 \%(16)$

Type of production

Native Multipurpose

$36 \%(56)$

Layers

Broiler for meat production

Types of record

Health care (Drug \& treatment record)

Feed records

$46 \%(71)$

Income record

$42 \%(65)$

No records

$5 \%(8)$

Source: Field data, 2020-2021. Key: $\mathrm{n}=156$; \%, percentage; <, less than; >, greater than.

Table 2. Role played by farmers on the use of veterinary antimicrobials in commercial poultry production systems in Kiambu County.

\begin{tabular}{|c|c|}
\hline \multicolumn{2}{|l|}{$(\mathrm{N}=156)$} \\
\hline Variables & Frequency (\%) \\
\hline \multicolumn{2}{|l|}{ How were the antimicrobial obtained? } \\
\hline Through prescription by the veterinary officer & $87 \%(136)$ \\
\hline Personal experience & $67 \%(104)$ \\
\hline Fellow farmer & $8 \%(13)$ \\
\hline \multicolumn{2}{|l|}{ Do you get advice on how to use antimicrobial agents? } \\
\hline Yes & $86 \%$ \\
\hline No & $14 \%$ \\
\hline \multicolumn{2}{|l|}{ If yes from whom? } \\
\hline Drug shop seller & $57 \%$ \\
\hline Veterinarian & $84 \%$ \\
\hline From a CBAHW in the area & $21 \%$ \\
\hline From a fellow Farmer & $32 \%$ \\
\hline All of the above & $1 \%$ \\
\hline Others (workers, Human clinics) & $1 \%$ \\
\hline \multicolumn{2}{|l|}{ Do you follow the advice given? } \\
\hline Yes & $85 \%$ \\
\hline No & $15 \%$ \\
\hline \multicolumn{2}{|l|}{ Were you satisfied with the quality of advice provided? } \\
\hline Yes & $85 \%$ \\
\hline No & $15 \%$ \\
\hline
\end{tabular}




\section{Continued}

What is the nearest distance from where you get your veterinary services?

Short distance $(1-2 \mathrm{~km})$

Medium distance (3 - $4 \mathrm{~km})$

$46 \%$

Long distance (Above $5 \mathrm{~km}$ )

$21 \%$

Key: \%—percentage; $\mathrm{Km}$-Kilometer; CBAHW—Community based animal health worker; $\mathrm{n}$ - sample size.

Table 3. Scrutinizing and assessing the major challenges facing Kiambu County poultry farmers on antibiotic use.

\begin{tabular}{ll}
\hline \multicolumn{2}{c}{$(\mathrm{N}=156)$} \\
\hline Variables & Frequency (\%)
\end{tabular}

What are the major challenges in accessing antimicrobials?

$\begin{array}{cc}\text { Drugs not available in the market } & 12 \% \\ \text { Long distances from the source } & 22 \% \\ \text { Lack of money to buy the drugs } & 49 \% \\ \text { They are expensive } & 72 \% \\ \text { All of the above } & 30 \% \\ \text { No challenges } & 1 \%\end{array}$

What challenges are there regarding the use of antimicrobials?

Lack of knowledge on antibiotic drug use $\quad 51 \%$

Unfamiliar language used in the inserts on their use $\quad 34 \%$

Lack of efficacy and effectiveness to treat infections $\quad 14 \%$

No challenges

What are the challenges regarding dosage formulation?

Dosage calculation and estimation difficult $\quad 15 \%$

Hard to follow dosage guideline on the leaflet $\quad 22 \%$

Lack of specific measuring containers $\quad 58 \%$

No challenges $\quad 8 \%$

What are challenges regarding quality of the drug?

Some drugs are fake $\quad 1 \%$

Some drugs are very expensive $\quad 94 \%$

No challenges $\quad 5 \%$

What are some of the challenges regarding service providers?

Lack of veterinary officers $\quad 77 \%$

Lack of CBAHW $\quad 28 \%$

Lack of consultation services $\quad 72 \%$

No challenges $\quad 13 \%$

Key: CBAHW-Community based animal; health worker; \%-percentage; Source: Field data November 2020 to February 2021. 
Table 4. Preferred types of antimicrobial agents stocked and used in the management of Diarrhea (Profuse, Acute, and Chronic); Sudden death; Emaciation; Swollen eyes with watery discharge in commercial poultry production in Kiambu County.

\begin{tabular}{|c|c|c|c|c|c|}
\hline \multirow{3}{*}{ Variables } & \multicolumn{5}{|c|}{$(N=156)$} \\
\hline & \multicolumn{5}{|c|}{ Frequency (\%) } \\
\hline & $\begin{array}{l}\text { Type } \\
\text { stocked }\end{array}$ & Diarrhea & $\begin{array}{l}\text { Sudden } \\
\text { Death }\end{array}$ & Emaciation & $\begin{array}{c}\text { Swollen } \\
\text { eyes }\end{array}$ \\
\hline None of the above & $1 \%$ & $1 \%$ & $2 \%$ & $54 \%$ & $3 \%$ \\
\hline $\begin{array}{l}\text { Tetracycline's (1a. Tetracyclines; 1b. } \\
\text { Oxytetracyclines; 1c. Doxycycline) }\end{array}$ & $63 \%$ & $60 \%$ & $56 \%$ & $29 \%$ & $60 \%$ \\
\hline $\begin{array}{l}\text { Amoxicillin (2a. Hipramox p powder; } \\
\text { 2b. Amoxi; 2c. Sacox; 2d, Panacur) }\end{array}$ & $32 \%$ & $29 \%$ & $29 \%$ & $42 \%$ & $30 \%$ \\
\hline Sulfadimidine (3). sulfadimethoxine) & $48 \%$ & $40 \%$ & $40 \%$ & $52 \%$ & $44 \%$ \\
\hline Enrofloxacine (4a) Hipralonaenro. $S^{\varpi}$ ) & $50 \%$ & $51 \%$ & $51 \%$ & $53 \%$ & $51 \%$ \\
\hline $\begin{array}{c}\text { Amprolium "powder (5a) Amprolium } \\
\text { hydrochloride) }\end{array}$ & $45 \%$ & $52 \%$ & $51 \%$ & $23 \%$ & $51 \%$ \\
\hline Diaziprim ${ }^{\oplus}$ powder & $21 \%$ & $24 \%$ & $23 \%$ & $17 \%$ & $21 \%$ \\
\hline Poltricin ${ }^{\circ}$ powder & $13 \%$ & $17 \%$ & $17 \%$ & $5 \%$ & $13 \%$ \\
\hline Penicillin G/Benzylpenicillin & $6 \%$ & $6 \%$ & $6 \%$ & $32 \%$ & $6 \%$ \\
\hline Erythromycin/Tylosin & $28 \%$ & $32 \%$ & $30 \%$ & $24 \%$ & $31 \%$ \\
\hline $\begin{array}{c}\text { Neomycin } \\
\text { sulfate/Streptomycin/Spectinomycin }\end{array}$ & $26 \%$ & $21 \%$ & $23 \%$ & $1 \%$ & $24 \%$ \\
\hline OTC dawa & $4 \%$ & $1 \%$ & $1 \%$ & $6 \%$ & $1 \%$ \\
\hline Aliseryl & $21 \%$ & $5 \%$ & $5 \%$ & $3 \%$ & $6 \%$ \\
\hline Colesultrix & $3 \%$ & $3 \%$ & $3 \%$ & $22 \%$ & $3 \%$ \\
\hline Miramed & $7 \%$ & $22 \%$ & $22 \%$ & $3 \%$ & $21 \%$ \\
\hline If not indicated on the list & $1 \%$ & - & - & $8 \%$ & $2 \%$ \\
\hline \multicolumn{6}{|c|}{ Please confirm which type of Tetracyclines? $(n=98)$} \\
\hline Tetracycline's & $9 \%$ & $9 \%$ & $9 \%$ & $9 \%$ & $9 \%$ \\
\hline Oxytetracyclines & $85 \%$ & $86 \%$ & $86 \%$ & $86 \%$ & $86 \%$ \\
\hline Doxycycline & $35 \%$ & $31 \%$ & $31 \%$ & $31 \%$ & $31 \%$ \\
\hline \multicolumn{6}{|c|}{ Please confirm which type of Amoxicillin $(n=49)$} \\
\hline Hipramox $\mathrm{p}^{\oplus}$ powder & $18 \%$ & $13 \%$ & $13 \%$ & $13 \%$ & $13 \%$ \\
\hline Amoxi & $88 \%$ & $91 \%$ & $91 \%$ & $91 \%$ & $91 \%$ \\
\hline Sacox & $2 \%$ & $2 \%$ & $2 \%$ & $2 \%$ & $2 \%$ \\
\hline
\end{tabular}

Key: —-Trade name; \%—Percentage; n—sample size; Source: Field data November 2020 to February 2021.

Kiambu County. We found that Tetracycline's (60\%), Amprolium ${ }^{\circledR}$ powder (52\%), Enrofloxacine (51\%), and Sulfadimidine (40\%) are the most commonly preferred agents in the management of this condition with Oxytetracyclines (86\%) and Amoxi (91\%) being the most used sub-types as shown in Table 4 above. 


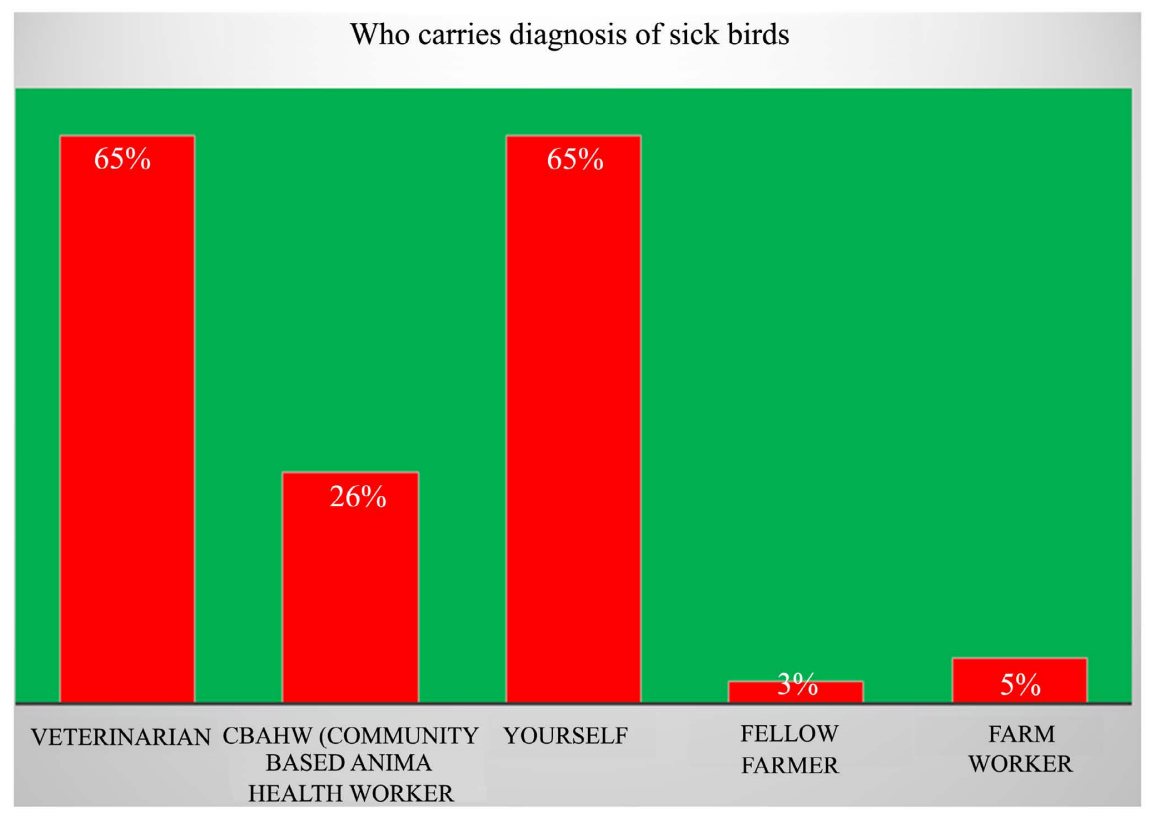

Figure 2. Who carries the diagnosis of the sick birds in the farms.

\subsection{Alternative Natural Remedies Used by Poultry Farmers in Disease Management in Kiambu County}

Table 5 presents the results on knowledge and practices on the use of alternative natural remedies in poultry disease management in Kiambu County. Ninety-two percent (92\%) of the farmers who responded said that they use natural herbal remedies in the management of poultry diseases. Most of the farmers indicated that they use Aloe vera (100\%), Capsicum annum (67\%), with both Livergenplus and Moringa Oelifera having $8 \%$ response to use. The farmers further highlighted that they use this natural remedy for both disease treatment and as growth promoter $(58 \%)$, with treatment scoring $33 \%$. The diseases that are mostly treated with natural remedies are Newcastle (78\%), Coccidiosis (64\%), diarrhea (50\%), and fowl typhoid (21\%) respectively as shown in Table 5 below.

\subsection{Knowledge and Practice of Farmers Withdraw Period after Treating Poultry Antibiotics}

Table 6 presents the results about knowledge and practices on the observation of the withdrawn period post-antibiotic use in poultry production. Eighty-two farmers $(82 \%)$, indicated that they understood the importance of observing withdrawn period post-antibiotic use. It was further noted that $91 \%$ of farmers observe withdrawal period to ensure the safety of animal production towards the consumer. This claim was further supported by $7 \%$ of the farmers who indicated that as the withdrawal period is not observed, the quality of the poultry products will be affected. In addition, more than half of the farmers (51\%) seemed not to understand the health implications of antimicrobial residues due to consuming products with residues. Majority of the poultry farmers attributed the health implication of consuming products with residues due to allergies (58\%), toxicity to 
Table 5. Alternative remedies to conventional medicine used in poultry disease management in Kiambu County.

\begin{tabular}{lll}
\hline & $(\mathrm{N}=156)$ & \\
\hline Variables & Frequency (\%) \\
\hline
\end{tabular}

Do you use alternative remedies/treatment apart from these antimicrobials?

Yes
No
No

Name the alternative natural remedies you use to treat your birds $(n=12)$

$\begin{array}{cc}\text { Aloe vera } & 100 \% \\ \text { Capsicum annum } & 67 \% \\ \text { Livergenplus } & 8 \% \\ \text { Moringa oleifera } & 8 \%\end{array}$

What purpose do you use these natural remedies for in poultry production? $(n=12)$

$\begin{array}{lc}\text { For treatment } & 33 \% \\ \text { To promote growth } & 8 \% \\ \text { All of the above } & 58 \%\end{array}$

Which diseases are they applied to if they are used for treatment/prophylaxis? $(n=14)$

$\begin{array}{cc}\text { Coccidiosis } & 64 \% \\ \text { Newcastle } & 71 \% \\ \text { Diarrhea } & 50 \% \\ \text { Gumboro } & 7 \% \\ \text { Immune Booster } & 7 \% \\ \text { Fowl Typhoid } & 21 \% \\ \text { Growth Promoter } & 7 \% \\ \text { Liver Toxicity } & 7 \%\end{array}$

Key: \%—percentage, ${ }^{\oplus}$ —Trademark, n—sample size; Source: Research data November 2020 to February 2021.

Table 6. Knowledge and practice of farmers on withdrawal period after treating poultry antibiotics.

\begin{tabular}{|c|c|}
\hline \multicolumn{2}{|l|}{$(\mathrm{N}=156)$} \\
\hline Variables & Frequency (\%) \\
\hline \multicolumn{2}{|c|}{ Do you think it's important to observe the withdrawal period? $(n=156)$} \\
\hline Yes & $82 \%$ \\
\hline No & $18 \%$ \\
\hline \multicolumn{2}{|c|}{ If yes, why do you think it is important to observe withdrawal period $(n=128)$} \\
\hline Food safety & $91 \%$ \\
\hline To prevent drug resistance & $4 \%$ \\
\hline To prevent deaths and allergic rxns & $1 \%$ \\
\hline Quality of poultry product & $7 \%$ \\
\hline
\end{tabular}




$\begin{array}{cc}\text { Palatability } & 5 \% \\ \text { Marketability } & 2 \% \\ \text { To give time for the birds to utilize drug in their bodies } & 1 \% \\ \text { Do you know any health implication associated with consuming animal products } \\ \text { contaminated with antimicrobial residues? }(\mathbf{n}=\mathbf{1 5 6}) \\ \text { Yes } & 49 \% \\ \text { No } & 51 \% \\ \text { If yes, which ones (Health implications)? }(\mathbf{n}=\mathbf{7 6}) & \\ \text { Toxicity to Human being } & 34 \% \\ \text { Allergies } & 58 \% \\ \text { Resistance to antimicrobial drugs } & 6 \% \\ \text { Lack of market } & 1 \% \\ \text { Diarrhea } & 49 \% \\ \text { Unpalatability } & 1 \%\end{array}$

Key: \%—percentage, ๑-Trademark, n—sample size; Source: Research data November 2020 to February 2021.

human beings (34\%) with the least of farmers indicating lack of product marketability and unpalatability (1\%) respectively due to residues presence as indicated in Table 6 above.

\subsection{Possible solutions mentioned by the poultry farmers that could help to curtail the challenges they are facing in poultry production systems in Kenya}

Table 7 presents the results of the possible solutions that were given by farmers towards curtailing some of the challenges they face in commercial poultry production in Kiambu County. More than half of the farmers suggested the need for continued training of the farmers on prudence and use of antibiotics (57\%) in the management of commercial poultry diseases. Furthermore, $28 \%$ of the farmers suggested the need to have well-trained extension veterinary officers who will be guiding and providing consultative services to the farmers on prudence and use of antimicrobial agents together with the management of commercial poultry diseases. The accessibility and availability of markets for poultry products (19\%), provision of cheap antimicrobial drugs (17\%), more effective drugs (6\%), affordable feeds (3\%) and government regulation and control of poultry feed prices (2\%) were some of the major solutions that would help to tame down the major challenges there poultry framer face in their daily production systems respectively as indicated in Table 7 below.

Table 8 presents the results of the relationship between socio-demographic factors and the challenges commercial poultry farmers face on their access. The results revealed that there was a statistically significant association between nearness to veterinary services $(\mathrm{P}<0.05)$ and the challenges that farmers face in accessing antimicrobial agents. The rest of the sociodemographs had no significant $(\mathrm{P}>0.05)$ statistical association with challenges affecting farmers towards accessing antimicrobial agents as shown in Table 8 below. 
Table 7. Some of the possible solutions suggested by commercial poultry farmers in Kiambu County that might scale down the problems they face in poultry farming.

\begin{tabular}{cc}
\hline \multicolumn{1}{c}{$(\mathrm{N}=156)$} & Frequency $(\%)$ \\
\hline $\begin{array}{c}\text { Variables } \\
\text { What are the possible solutions to the above-mentioned challenges facing poultry } \\
\text { farmers with the use of antimicrobial agents and in the management of poultry } \\
\text { production systems in Kenya? }\end{array}$ & $57 \%$ \\
Training of farmers on prudence use of antibiotics & $39 \%$ \\
Well trained Extention veterinary officers & $19 \%$ \\
Market accesibility/availability & $17 \%$ \\
Affordable feeds & $3 \%$ \\
Government to control and regulate food price & $2 \%$ \\
Introduction of another source of food & $1 \%$ \\
More effective drugs & $6 \%$ \\
To observe withdraw to poultry farmer & $1 \%$ \\
None & $1 \%$ \\
\hline
\end{tabular}

Key: \%—percentage, n—sample size; Source of data: Research data November 2020 to February 2021.

Table 8. Relationship between socio-demographic factors and the challenges in accessing and use of antimicrobial agents stocked as analyzed by Chi-square.

\begin{tabular}{ccc}
\hline Study Variable & \multicolumn{2}{c}{ Chi square $\left(\mathrm{X}^{2}\right) ;(\mathrm{P}-$ Value $<0.05)$} \\
\cline { 2 - 3 } Gender & $\mathrm{X}^{2}=7.907(0.161)$ & $\mathrm{X}^{2}=1.900(0.593)$ \\
Male & & \\
Female & $\mathrm{X}^{2}=5.271(0.984)$ & $\mathrm{X}^{2}=14.668(0.100)$ \\
Age (Yrs) & & \\
$15-25$ & & \\
$26-35$ & & \\
$36-45$ & & \\
$>45$ & $\mathrm{X}^{2}=2.990(0.701)$ & \\
Marital status & & \\
Single & & \\
Married & & \\
Divorced & & \\
Education level \\
Primary \\
Secondary \\
Certificate
\end{tabular}




\section{Continued}

\begin{tabular}{|c|c|c|}
\hline \multicolumn{3}{|l|}{ Diploma } \\
\hline \multicolumn{3}{|l|}{ Master's degree } \\
\hline \multicolumn{3}{|l|}{ No formal education } \\
\hline Region/area of residence & $\mathrm{X}^{2}=11.934(0.290)$ & $\mathrm{X}^{2}=82.037\left(0.000^{*}\right)$ \\
\hline \multicolumn{3}{|l|}{ Gatundu North } \\
\hline \multicolumn{3}{|l|}{ Gatundu south } \\
\hline \multicolumn{3}{|l|}{ Juja } \\
\hline \multicolumn{3}{|l|}{ Kikuyu } \\
\hline \multicolumn{3}{|l|}{ Ruiru } \\
\hline \multicolumn{3}{|l|}{ Thika } \\
\hline Designation & & $\mathrm{X}^{2}=13.715\left(0.033^{\star}\right)$ \\
\hline \multicolumn{3}{|l|}{ Layer farmer } \\
\hline \multicolumn{3}{|l|}{ Broiler farmer } \\
\hline \multicolumn{3}{|l|}{ Multipurpose farmer } \\
\hline No of years in poultry farming & $\mathrm{X}^{2}=20.484(0.903)$ & $\mathrm{X}^{2}=36.723\left(0.006^{*}\right)$ \\
\hline \multicolumn{3}{|l|}{ Less than $1 \mathrm{yr}$} \\
\hline \multicolumn{3}{|l|}{ One year } \\
\hline \multicolumn{3}{|l|}{ Two years } \\
\hline \multicolumn{3}{|l|}{ Three years } \\
\hline \multicolumn{3}{|l|}{ Four years } \\
\hline \multicolumn{3}{|l|}{ Five years } \\
\hline \multicolumn{3}{|l|}{$>5 \mathrm{yrs}$} \\
\hline Average No. of birds kept & $\mathrm{X}^{2}=8.394(0.907)$ & $\mathrm{X}^{2}=17.047\left(0.048^{\star}\right)$ \\
\hline \multicolumn{3}{|l|}{$<50$} \\
\hline \multicolumn{3}{|l|}{$50-500$} \\
\hline \multicolumn{3}{|l|}{$501-1000$} \\
\hline \multicolumn{3}{|l|}{$1001-5000$} \\
\hline Nearness to veterinary services & $\mathrm{X}^{2}=32.105\left(0.000^{\star}\right)$ & $\mathrm{X}^{2}=15.471\left(0.017^{\star}\right)$ \\
\hline
\end{tabular}

Key: $\mathrm{X}^{2}$-Chi-square; ${ }^{*}$-Statistically significance; $\mathrm{df}$-degrees of freedom.

Table 9 presents the results of the relationship between regions of residence and the knowledge, attitudes, and practices on the type of antimicrobial agents stocked by farmers. The area of residence statistically significant $(P<0.05)$ influenced majority of the parameters that were used to access the level of knowledge, attitudes, and practices on the type of antimicrobial agents stocked by farmers in Kiambu County as shown in Table 9 below.

Table 10 presents the results on how age is statistically significant $(\mathrm{P}<0.05)$ 
Table 9. Relationship between area/region of residence designation and knowledge, attitudes, and practices on the type of antimicrobial agents stocked by farmers as analyzed by Chi-square.

\begin{tabular}{|c|c|c|}
\hline \multirow{2}{*}{ Study variables } & \multicolumn{2}{|c|}{ Chi square $\left(X^{2}\right),(d f)(P$-value $\left.)\right)$} \\
\hline & Areas of residence & Designation \\
\hline $\begin{array}{l}\text { Type of antimicrobial agents stoked } \\
\text { by the farmers }\end{array}$ & $157.572(75)\left(0.000^{*}\right)$ & $55.052(30)\left(0.04^{\star}\right)$ \\
\hline $\begin{array}{c}\text { Type/class of antimicrobial currently } \\
\text { used by farmers }\end{array}$ & $181.069(80)\left(0.000^{\star}\right)$ & $59.393(32)\left(0.02^{\star}\right)$ \\
\hline $\begin{array}{l}\text { Use of antimicrobial to treat Diarrhea } \\
\text { (Profuse, acute, Chronic) }\end{array}$ & $190.117(80)\left(0.000^{*}\right)$ & $60.229(32)\left(0.02^{\star}\right)$ \\
\hline Use of antimicrobial to treat sudden death & $188.834(85)\left(0.000^{*}\right)$ & $46.163(34)\left(0.80^{*}\right)$ \\
\hline Use of antimicrobial to treat emaciation & $192.520(80)\left(0.000^{*}\right)$ & $42.273(32)\left(0.105^{\star}\right)$ \\
\hline $\begin{array}{l}\text { Use of antimicrobial to treat swelling eyes } \\
\text { with watery discharge }\end{array}$ & $260.757(85)\left(0.000^{*}\right)$ & $75.306(34)\left(0.000^{*}\right)$ \\
\hline What production type of birds do you have? & $53.102(15)\left(0.000^{\star}\right)$ & $163.557(6)\left(0.000^{*}\right)$ \\
\hline What type of records do you keep? & $30.002(15)\left(0.012^{\star}\right)$ & $20.134(6)\left(0.003^{\star}\right)$ \\
\hline $\begin{array}{l}\text { Who carries diagnosis of sick birds/tells } \\
\text { bird are sick }\end{array}$ & $59.354(25)\left(0.000^{*}\right)$ & \\
\hline How do you tell that the birds are sick? & $48.668(25)\left(0.003^{\star}\right)$ & \\
\hline Who does the treatment of your sick birds? & $87.087(20)\left(0.000^{\star}\right)$ & $18.303(8)\left(0.019^{*}\right)$ \\
\hline What is your source of antimicrobial? & $32.612(20)\left(0.037^{\star}\right)$ & \\
\hline How were the antimicrobial obtained? & $22.425(10)\left(0.013^{\star}\right)$ & \\
\hline If yes, From who? & $48.857(25)\left(0.003^{\star}\right)$ & \\
\hline $\begin{array}{l}\text { What are the major challenges in accessing } \\
\text { antimicrobial agents? }\end{array}$ & $38.877(25)\left(0.038^{\star}\right)$ & \\
\hline $\begin{array}{l}\text { What challenges are there regarding } \\
\text { the use of antimicrobials? }\end{array}$ & $82.037(15)\left(0.000^{\star}\right)$ & $13.715(6)\left(0.033^{\star}\right)$ \\
\hline $\begin{array}{c}\text { What are the challenges regarding } \\
\text { dosage formulation? }\end{array}$ & $45.720(15)\left(0.000^{*}\right)$ & \\
\hline $\begin{array}{l}\text { What are some of the challenges } \\
\text { regarding the service provider? }\end{array}$ & $53.903(15)\left(0.000^{*}\right)$ & $22.242(6)\left(0.001^{\star}\right)$ \\
\hline $\begin{array}{l}\text { Why do you think it is important } \\
\text { to observe withdraw periods }\end{array}$ & $58.650(30)\left(0.001^{\star}\right)$ & \\
\hline $\begin{array}{l}\text { Knowledge on effect of drug residues } \\
\text { presence in poultry products }\end{array}$ & $82.579(35)\left(0.000^{*}\right)$ & \\
\hline $\begin{array}{l}\text { What are the possible solutions to the } \\
\text { above-mentioned challenges facing poultry } \\
\text { farmers on the use of antimicrobial in Kenya? }\end{array}$ & $139.771(50)\left(0.000^{*}\right)$ & $32.937(20)\left(0.034^{*}\right)$ \\
\hline
\end{tabular}

Key: $\mathrm{X}^{2}$-Chi-square; ${ }^{*}$-Statistically significance; $\mathrm{df}$ - degrees of freedom.

influences on who does the treatment of sick birds, and knowledge and practice on the importance of observation of withdrawn periods as shown in Table 10 below.

Table 11 presents the results on how the size of stocked birds influences 
Table 10. Relationship between age of farmers, level of education, experience, and knowledge, attitudes, and practices in commercial poultry production systems of Kiambu County as analyzed by Chi-square.

\begin{tabular}{|c|c|c|c|}
\hline \multirow{2}{*}{ Study variables } & \multicolumn{3}{|c|}{ Chi square $\left(\mathrm{X}^{2}\right),(\mathrm{df}),(\mathrm{P}$-value $)$} \\
\hline & Age & Education level & Experience \\
\hline $\begin{array}{l}\text { Who does the treatment } \\
\text { of your sick birds? }\end{array}$ & $30.833(12)\left(0.002^{\star}\right)$ & $39.967(24),\left(0.022^{*}\right)$ & $36.739(24)\left(0.046^{\star}\right)$ \\
\hline $\begin{array}{l}\text { Why do you think it is } \\
\text { important to observe } \\
\text { withdraw periods }\end{array}$ & $29.465(18)\left(0.043^{*}\right)$ & - & - \\
\hline $\begin{array}{l}\text { Knowledge on effect/impact } \\
\text { of drug residues presence } \\
\text { in poultry products }\end{array}$ & - & $136.446(42)\left(0.000^{\star}\right)$ & $68.418(42)\left(0.006^{*}\right)$ \\
\hline $\begin{array}{l}\text { What challenges are there } \\
\text { regarding the use of } \\
\text { antimicrobials? }\end{array}$ & - & - & $36.723(18)\left(0.006^{*}\right)$ \\
\hline
\end{tabular}

Key: $\mathrm{X}^{2}$-Chi-square; ${ }^{*}$-Statistically significance; $\mathrm{df}$ - degrees of freedom.

Table 11. Impact of the number of birds stocked in commercial poultry production on knowledge, attitudes, and practices on antimicrobial use as analyzed by Chi-square.

\begin{tabular}{|c|c|c|}
\hline What average number of birds do you keep? & $\begin{array}{c}\text { Chi square }\left(\mathrm{X}^{2}\right) \text {, } \\
\text { (df) }\end{array}$ & P-Value \\
\hline What production type of birds do you have? & $20.271(9)$ & $0.016^{*}$ \\
\hline What type of records do you keep? & $20.339(9)$ & $0.016^{*}$ \\
\hline Who carries diagnosis of sick birds/tells the bird is sick? & $25.599(15)$ & $0.042^{*}$ \\
\hline Who does the treatment of your sick birds? & $33.132(12)$ & $0.001^{*}$ \\
\hline What challenges are there regarding the use of antimicrobials? & $17.047(9)$ & $0.048^{*}$ \\
\hline $\begin{array}{l}\text { What are the possible solutions to the above-mentioned } \\
\text { challenges facing poultry farmers on the use of } \\
\text { antimicrobial agents in Kenya? }\end{array}$ & $53.514(30)$ & $0.005^{\star}$ \\
\hline
\end{tabular}

Key: $\mathrm{X}^{2}-$ Chi-square; ${ }^{*}$-Statistically significance; $\mathrm{df}$-degrees of freedom.

knowledge, attitudes, and practices on antimicrobial use by poultry commercial farmers of Kiambu County. The result reveals that there was a significant $(\mathrm{P}<$ 0.05 ) association about the number of birds stocked with the factors presented that were used to access the level of knowledge, attitudes, and practices on antimicrobial use as in Table 11 above.

Table 12 presents the results on how the distance travelled to access veterinary services influence the level of knowledge, attitudes, and practices on antimicrobial use in commercial poultry production systems. The results revealed a significant association between the distances travelled to access veterinary services with knowledge on challenges affecting farmers on accessing antimicrobial agents, their use, and regarding the service providers' accessibility as indicated in Table 12 below. 
Table 12. Impact of distance to access veterinary services in commercial poultry production on knowledge, attitudes, and practices on antimicrobial use as analyzed by Chisquare.

\begin{tabular}{ccc}
\hline What is the nearest from where you get your veterinary services? & $\begin{array}{c}\text { Chi square }\left(\mathrm{X}^{2}\right), \\
(\mathrm{df})\end{array}$ & P-Value \\
\hline What are the major challenges in accessing antimicrobials? & $32.105(10)$ & $0.000^{*}$ \\
What challenges are there regarding the use of antimicrobials? & $15.471(6)$ & $0.017^{\star}$ \\
What are some of the challenges regarding the service provider? & $21.198(6)$ & $0.002^{*}$ \\
\hline
\end{tabular}

Key: $\mathrm{X}^{2}$-Chi-square; ${ }^{*}-$ Statistically significance; $\mathrm{df}$-degrees of freedom.

\section{Discussion of Research Findings}

The usage of antimicrobial drugs in poultry production is essential in disease treatment, prevention, and growth promoting, but its use must be accepted as a responsibility rather than a right when trying to improve poultry health by Rose et al. [9]. This will help to minimize the potential risk and hazards due to poor drug use of antimicrobial agents in livestock production. Therefore, the use of veterinary antibiotic drugs in poultry systems needs proper control through legislation bodies with the broad goals to preserve animal health, improve animal production, and to protect the public by Cardona \& Kuney [10]. Resistance to antimicrobial agents is significantly growing in almost all populations. This increase can be associated due to lack of adequate knowledge and poor practice on the prudence, to use antimicrobial agents in the management of poultry diseases, and inappropriate attitudes towards their usage for prophylaxis and as growth promoters. This has promptly contributed to the occurrence of Multi-drug resistance microbes and offload of residues in poultry products, hence affecting the international market trade. This being the first cross-sectional study to be carried out in Kiambu County on the level of knowledge, attitudes, and practices on antimicrobial use in commercial poultry production will help to unravel potential mitigation and measures in policy making to help curb antimicrobial resistance across the country.

The study demonstrated that $2 / 3^{\text {rd }}$ of the farmers were Females $(68 \%)$, married $(91 \%)$, aged above 45 years, and had attained secondary education level and they preferred keeping layer birds. This agrees according to FAO [11], that most farmers prefer keeping layers in medium and large scale under intensive management. This is attributed to the great demand for eggs in urban areas and the high profit margin associated to layers than broilers. This could further be attributed to the fact that most women are left at home while taking care of the livestock and being the majority are above $45 \mathrm{yrs}$ age, which could be as a result of the retirement plan scheme being that poultry care does not require a lot of capital and space to invest in. This agrees with the study carried out by Calvin et al. [12] in Tanzania. We further noted that Kikuyu subcounty was leading in commercial layer production systems seconded by Ruiru to Gatundu south having the least of poultry production activity. This agrees with the study carried out by 
Okello et al. [13], Mbugua et al. [14] and ROK [15]. It was further noted that the majority of the farmers are small-scale farmers (101 - 500 birds) which agrees with the study carried out by Nyaga [8]. This could be as a result of little capital to keep large scale production. We also noted that the majority of the farmers prefer to keep feed and income records compared to antibiotic records. This could be explained by the need of farmers to maximize profit and lessen expenditure as antibiotics are sometimes little concern due to ignorance and not knowing the great danger they can expose to both animals and humans.

In the study, we found that the majority of the Socio-demographic characteristics did not significantly $(\mathrm{P}>0.05)$ influence the ability to access antimicrobial agents, however, nearness to veterinary services significantly $(\mathrm{P}<0.05)$ contributed to the use of antimicrobial agents in the farms. We also found that the area/region of residence was statistically significantly $(P<0.05)$ associated with the challenges that the farmers were facing from antimicrobial use, with Kikuyu farmers less affected due to their extensive history of commercial poultry production. This agrees with a study that was carried out by Mbugua et al. [14] who found that the majority of Kiambu farmers came from Kikuyu Sub-County.

We further noted that there was a significant $(\mathrm{P}<0.05)$ relationship between the level of experience and who treats the sick birds, challenges on the use of antimicrobial agents and on knowledge on the effects of eating poultry products with the presence of residues. The years of experience in commercial poultry production had positive impacts on the level of knowledge, attitudes, and practices on antimicrobial use in poultry production systems. Higher experience level would help most of the farmers to observe, withdraw periods, and ensure prudence use of antimicrobial agents in poultry farming. We further noted that commercial farmers who kept medium and large scale stock significantly $(\mathrm{P}<$ 0.05 ) had adequate knowledge and experience on antimicrobial agent use, record keeping, proper way of disease diagnosis and treatment and knowledge on possible solutions to avert problems that affect them in commercial poultry farming. This could be attributed to the heavy investment they have engaged in and they could take any measures to avert any situation that could halt their production.

From the study, we found that most of the farmers acquire this antibiotic through prescription by veterinary officers, which disagrees with a study carried out by Lindonne Glasgow et al. [16], who found that the majority of antibiotics users are self-prescribers. Furthermore, we noted that most of the farmers claim that they follow the advice they get from the veterinary officers on the use of antimicrobial agents which disagrees with the study carried out by Calvin Sindato et al. [12] who claimed most of the antibiotic users do not follow the guidelines of the prescriber. We also found that the majority of the farmers walk medium distances $(3-4 \mathrm{~km})$ in order to access this antimicrobial agent. The need for close access to veterinary services is very crucial to commercial poultry farmers to ensure they get the right advice and services on time and this might help to stem down the imprudent use of antimicrobial agents as stated by Aniroot 
Nuangmek et al. [17]. It was further noted that the majority of cases of sick birds are noted and reported by the farmers themselves who lacked credible skills, instead of engaging well-trained veterinary extension field officers. This could be attributed due to the lack of enough veterinarians and consultative services to poultry farmers who mostly own small and medium scale farms. This is more so supported by the results in Figure 2, which indicate that both the veterinarian and the farmer have an equal propensity of diagnosing sick birds, hence the farmer uses his experience instead of well trained personnel to treat and diagnose the sick. This could be one of the ways of promoting irrational use of antimicrobial agents by untrained persons. Additional, we identified that the majority of the farmers get their antimicrobial agents from drug shops through personal experience, this agrees with a study that was carried out in Thailand by Aniroot Nuangmek et al. [17] who found that the majority of farmers understood the need for professional antimicrobial prescription but due to ignorance they disregarded this practice. This further exonerates that most of the commercial poultry farmers have inaccurate attitudes and practices that exhibit inappropriate towards behavior antimicrobial use.

Furthermore, we found that the majority of the farmers still find most of the antibiotics to be expensive for them to afford despite them having inadequate knowledge on the proposed use of antimicrobial agents. The commercial poultry farmers further claimed that antibiotics have inserts that have unfamiliar language and they do not have proper measuring containers that would culminate with either overdose or under a dose of drugs. This might lead to a lack of effectiveness and efficiency of the antibiotics as was claimed by the farmers. Proper and adequate knowledge is very critical to the farmers to help ensure prudence and use of antimicrobial agents hence preventing future occurrence of antimicrobial resistance. This is corresponding to a study that was carried out by Casal et al. [18] who suggested that there is a need for efforts to increase farmer's awareness of biosecurity as a major input in stemming antimicrobial resistance in livestock production. Lack of enough veterinary extension officers and consultative services towards the use and preparation of antimicrobial agents among poultry farmers was also immensely experienced by the farmers. This could contribute greatly to the improper use of these drugs among the farmers in Kiambu County and across Kenya. According to a study carried out by Aniroot, Nuangmek et al. [17], he noted that adequately trained veterinarian officers are key to promoting appropriate antimicrobial usage on farms, because of their existing good reputation among farmers, and are perfectly suited to act as a waterway for informing farmers about antimicrobial resistance and the right application of antimicrobials agents in livestock disease management.

Similarly, we found that antimicrobial use is a common practice among commercial poultry farmers in Kiambu County. The types/class of antimicrobial agents that we found to be commonly used and preferred by commercial poultry farmers of Kiambu County were Tetracycline, Enrofloxacine, Sulfadimidine, and 
Amprolium compounds respectively, with Oxytetracyline and Amoxi sub-types of these drugs being highly mentioned. This could be associated with high cases of bacterial and protozoal infestation in poultry production. This same class of drugs was mentioned to be have been used previously in the last one year and currently in the farms. We also found that in the same order the drugs are used to manage diarrhea (acute, profuse, and chronic), emaciation, sudden death, and swelling of eyes with watery discharge. Oxytetracycline and sulfadimidine are a broad spectrum antibacterial drug and Amprolium is used to treat coccidiosis making them be on high demand in commercial poultry production. This creates an increased dependence on antibiotics as a substitute for good management practices such as good animal husbandry and housing hygiene as conferred by Rice and Straw [19]. According to a study carried out in Ethiopia by Gebeyehu E, Bantie L, and Azage M [20] and in Uganda by Ocan et al. [21], they found that continuous use of antimicrobial agents is a key determinant of antimicrobial resistance, especially when they are used inappropriately. It is therefore important to stipulate that these antimicrobial agents are at increased risk of developing bacteria resistance and high multidrug resistance in the near future as stated by Muhie [22]. Regarding Austin DJ, Kristinsson KG, and Anderson RM [23], the volume of drug use is a key selection pressure driving changes in the frequency of antimicrobial resistance in the community.

According to our study, the majority of the farmers observed withdrawing period's post-antibiotic use in their commercial poultry production systems to ensure the safety of the products to human health. However, the majority of the poultry farmers seemed not to understand the implication of having antibiotics residues in poultry products in human health. According to a study carried out in Kenya by Mitema et al. [24], they found that there was high level of antimicrobial residue contaminants in livestock meat, this could be explained by the fact that majority of the farmers in this study did not understand the health implication of this residue in animal products. In accordance with Bagley [25], this could be attributed to the lack of adequate awareness creation by all stakeholders on the public importance of drug residues. Allergies and diarrhea from eating poultry products contaminated with drugs residues were highly implicated in this study and according to Mubito [26]; WHO [27], this can constitute a potential hazard to the public health. This signifies that there is a need to create awareness and sensitize the commercial poultry farmers on the implication of not observing withdrawal periods and the detrimental effects of selling poultry products with antibiotic residues.

Due to the high prices of conventional antimicrobial agents, most of the commercial poultry farmers seemed to understand the use of natural herbal remedies in the management of diseases in their production systems. Aloe vera, Capsicum annum, Livergen plus, and Moringa oleifera preparations were noted to be used in treatment of the following disease conditions in commercial poultry production; Newcastle, coccidiosis, fowl typhoid and diarrhea. The use of alternative natural products in animal disease management has been promoted 
since they are cheap, readily available, efficacious, and regarded as safe (WHO), [27] [28], Ndukui et al. [29].

According to our results, we found that the majority of the farmers proposed the need for adequate training on prudence, and use of antimicrobial agents, the impacts of not observing the withdraw periods, and the effects of antibiotics residues on human health and the marketability of their products to the world market. These trainings to farmers would help to halt the escalating problem of antimicrobial resistance. We also found that there is a need for more adequately trained veterinary extension officers to provide consultative services to these farmers on the proper use of antibiotics and management of poultry diseases. This agrees with a study carried out by Aniroot Nuangmek et al. [17], who proposed the need for thorough and continuous efforts to train farmers on proper antimicrobial agent used in poultry production. He further states that the availability of well-trained veterinarians to the poultry farmers is a key intervention towards knowledge dissemination on prudence and application of antimicrobial agents. Furthermore, we realized that since the majority of farmers are small scale holder, there is a need for County government and the state government to provide funds to upscale their production systems which will result in a high source of income generation. There is also need for the government to control the prices of both antibiotics and feed, which have become a big challenge to the commercial poultry production system which agrees with a study carried out by Ling et al. [30] who stated that economic cost and benefits to the farmers are the first reasons making judgment on antimicrobial use, since they are much worried about financial implication than prudence use of this drugs. In 2004, Tollefson [31] in his study suggested that there is need of high quality regulatory government agencies in developing countries like Kenya to help in the management of emerging threats such as AMR. According to Lindonne et al. [16], Lowand middle-income countries are often more challenged in allocating adequate resources and instituting policies to address gaps in knowledge and practices in animal food production industries. Antibiotic use in food animals remains unregulated, leading to inappropriate use of drugs and a widespread increase in antibiotic resistance, hence the need for the government of the day to take caution and influence policies to stem down AMR.

\section{Conclusion}

Our current study underscores the understanding of the factors that contribute to antimicrobial misuse in commercial poultry production systems in Kiambu County, Kenya, and the results show there is a need for collaboration between the Ministry of Agriculture and Livestock Development, with the County government and the Ministry of Health to ascertain factors that promote antimicrobial use in the poultry and livestock industry by developing and distributing protocols to monitor the use of antimicrobial agents, and improve AMR surveillance in humans and livestock. 


\section{Acknowledgements}

The authors of this manuscript express their gratitude to everyone who contributed immensely to this research. Special thanks are due to Mr.Ayub Nguyo, $\mathrm{Mu}-$ thamia, Hesbone Masongo Onsoro, Paul Kimani Macharia, and Boniface Mwaura for their tireless contributions and commitment during fieldwork as research assistance. The authors also register thanks to Dr. John Mwaniki, at Centre for Microbiology Research (KEMRI), for his guidance and support in the conduct of this study.

\section{Conflicts of Interest}

The authors of this manuscript declare no conflict of interest whatsoever.

\section{Authors' Contribution}

JGN, JKG, GOA, and JMM conceptualized and designed the study. JGN conducted the study, collected data, and performed data analysis. JGN, JKG, GOA, and JMM interpreted the results and participated in the writing of the draft script and affirmed that the manuscript was an accurate and transparent account of the study being reported. JGN accept full responsibility for the work and the conduct of the study, and organized the decision to publish. The corresponding author confirms that all listed authors meet the authorship criteria and no others meeting the criteria have been omitted.

\section{Ethical Approval}

Ethical approval was obtained from the faculty of veterinary medicine board of postgraduate study and from NACOSTI (NACOSTI/P/21/8761) and from County Government of Kiambu Livestock, Fisheries and Veterinary services (KCG/ALF/ RESEARCH/VOL.1/49).

\section{Source of Funding}

The research study was partially funded by the National research fund Kenya (NRF/PHD/02/166).

\section{References}

[1] FAO (2010) Poultry Meat and Eggs. Agribusiness Hand Book. Food and Agricultural Organization, Rome.

https://dokumen.tips/business/fao-agribusiness-handbook-poultry-meat-eggs.html

[2] Speedy, A.W. (2002) Global Production and Consumption of Animal Source Foods. The Journal of Nutrition, 133, 4048S-4053S. https://doi.org/10.1093/jn/133.11.4048S

[3] Geidam, Y., Zakaria, Z., Aziz, S.A., Bejo, S.K., Abu, J. and Omar, S. (2012) High Prevalence of Multi-Drug Resistant Bacteria in Selected Poultry Farms in Selangor, Malaysia. Asian Journal of Animal and Veterinary Advances, 7, 891-897. https://doi.org/10.3923/ajava.2012.891.897

[4] Morley, P.S., Apley, M.D., Besser, T.E., et al. (2005) Antimicrobial Drug Use in Ve- 
terinary Medicine. Journal of Veterinary Internal Medicine, 19, 617-629. https://doi.org/10.1111/j.1939-1676.2005.tb02739.x

[5] Mellon, M., Benbrook, C. and Benbrook, K.L. (2001) Hogging It: Estimates of Antimicrobial Abuse in Livestock. Union of Concerned Scientists Publications, Cambridge.

[6] Kitzes-Cohen, R., Koos, D. and Levy, M. (2004) Patterns of Systemic Antibiotic Use in a Tertiary Hospital in Israel in the Years 1998-2000. The International Journal of Clinical Pharmacology and Therapeutics, 42, 246-252. https://doi.org/10.5414/CPP42246

[7] Apata, D.F. (2009) Antibiotic Resistance in Poultry. International Journal of Poultry Science, 8, 404-408. https://doi.org/10.3923/ijps.2009.404.408

[8] Nyaga, P.N. (2007) Avian Influenza Rapid Appraisal and Pro-Poor Livelihoods Consultation on Lessons Learned. Kenya Country Report, International Livestock Research Institute (ILRI), Nairobi City.

[9] Rose, J.M., Gast, R.J., Bogomolni, A., Ellis, J.C., Lentell, B.J., Touhey, K. and Moore, M. (2009) Occurrence and Patterns of Antibiotic Resistance in Vertebrates off the Northeastern United States Coast. FEMS Microbiology Ecology, 67, 421-431. https://doi.org/10.1111/j.1574-6941.2009.00648.x

[10] Cardona, C.J. and Kuney, D.R. (2002) Biosecurity on Chicken Farms. In: Commercial Chicken Meat and Egg Production, Springer US, Boston, 543-556. https://doi.org/10.1007/978-1-4615-0811-3_28

[11] FAO (2009) Global Livestock Production and Health Atlas. Food and Agriculture Organization, Rome. http://www.fao.org

[12] Sindato, C., Mboera, L.E.G., Katale, B.Z., et al. (2020) Knowledge, Attitudes and Practices Regarding Antimicrobial Use and Resistance among Communities of Ilala, Kilosa and Kibaha Districts of Tanzania. Antimicrobial Resistance \& Infection Control, 9, 194. https://doi.org/10.1186/s13756-020-00862-y

[13] Okeke, I.N., Klugman, K.P., Bhutta, Z.A., Duse, A.G., Jenkins, P. and O’Brien, T.F. (2015) Antimicrobial Resistance in Developing Countries. Part II: Strategies for Containment. The Lancet Infectious Diseases, 5, 568-580. https://doi.org/10.1016/S1473-3099(05)70217-6

[14] Mbugua, M.W. (2014) Analysis of Demand for Antibiotics in Poultry. MSc Final Thesis, Kenyatta University, Kahawa.

[15] Republic of Kenya (RoK) (2010) 2009 KenyaPopulation and Housing Census Analytical Reports.

https://www.knbs.or.ke/?p=517).\%20LET\%20THE\%20YEAR\%20BE\%202009

[16] Lindonne, G., Martin, F., Darren, B., Catherine, M., Stephanie, F. and Shelly, R. (2019) Antibiotic Use in Poultry Production in Grenada. Veterinary Medicine International, 2019, Article ID: 6785195. https://doi.org/10.1155/2019/6785195

[17] Aniroot, N., Suvichai, R., Suwit, C., Panuwat, Y., Pakpoom, T., Visanu, T., Nattasit, T. and Prapas, P. (2018) Antimicrobial Resistance in ESBL-Producing Escherichia coli Isolated from Layer and Pig Farms in Thailand. Acta Scientiae Veterinariae, 46, 1538. https://doi.org/10.22456/1679-9216.81823

[18] Casal, J., De Manuel, A., Mateu, E. and Martín, M. (2007) Biosecurity Measures on Swine Farms in Spain: Perceptions by Farmers and Their Relationship to Current On-Farm Measures. Preventive Veterinary Medicine, 82, 138-150. https://doi.org/10.1016/j.prevetmed.2007.05.012

[19] Rice, D.N. and Straw, B.E. (1992) Extension History Material from University of 
Nebrasska-Lincoln Etension, G92-1093. Use of Animal Drugs in Livestock Management.

[20] Gebeyehu, E., Bantie, L. and Azage, M. (2015) Inappropriate Use of Antibiotics and Its Associated Factors among Urban and Rural Communities of Bahir Dar City Administration, Northwest Ethiopia. PLoS ONE, 10, e0138179.

https://doi.org/10.1371/journal.pone.0138179

[21] Ocan, M., Bwanga, F., Bbosa, G.S., Bagenda, D., Waako, P. and Ogwal-Okeng, J. (2014) Patterns and Predictors of Self-Medication in Northern Uganda. PLoS ONE, 9, e92323. https://doi.org/10.1371/journal.pone.0092323

[22] Muhie, O.A. (2019) Antibiotic Use and Resistance Pattern in Ethiopia: Systematic Review and Meta-Analysis. International Journal of Microbiology, 2019, Article ID: 2489063. https://doi.org/10.1155/2019/2489063

[23] Austin, D.J., Kristinsson, K.G. and Anderson, R.M. (1999) The Relationship between the Volume of Antimicrobial Consumption in Human Communities and the Frequency of Resistance. Proceedings of the National Academy of Sciences of the United States of America, 96, 1152-1156. https://doi.org/10.1073/pnas.96.3.1152

[24] Mitema, E.S., Kikuvi, G.M., Wegener, H.C. and Stohr, K. (2001) An Assessment of Antimicrobial Consumption in Food Producing Animals in Kenya. Journal of Veterinary Pharmacology and Therapeutics, 24, 385-390. https://doi.org/10.1046/j.1365-2885.2001.00360.x

[25] Bagley, C.V. (2007) Food Fact Safety Sheet, Drug Residues and Food Safety.

[26] Mubito, F. (2014) Antimicrobial Use in the Poultry Industry and Public Health Implications in Tanzania. American Journal of Research Communication, 2, 2325 4076.

[27] WHO (2012) On the Medical Impact of Antimicrobial Use in Food Animals. Meeting Held in Berlin, German, 13-17 October.

[28] WHO (2009) WHO Monographs on Selected Medicinal Plants. Volume 4. Geneva.

[29] James, G.N., Mugisha, K., Owiny, D., Kateregga, J., Patrick, V., Kasolo, J. and Waako, P. (2014) Toxicity Profile of Aqueous Leaf Extracts of Citropsis articulata and Mystroxylon aethiopicum in Male Albino Rats. World Journal of Pharmaceutical Research, 3, 1273-1290.

[30] Ling Oh, A., Hassali, M.A., Al-Haddad, M.S., Syed Sulaiman, S.A., Shafie, A.A. and Awaisu, A. (2011) Public Knowledge and Attitudes towards Antibiotic Usage: A Cross-Sectional Study among the General Public in the State of Penang, Malaysia. The Journal of Infection in Developing Countries, 5, 338-347. https://doi.org/10.3855/jidc.1502

[31] Tollefson, L. (2004) Developing New Regulatory Approaches to Antimicrobial Safety. Journal of Veterinary Medicine B, Infectious Diseases and Veterinary Public Health, 51, 415-418. https://doi.org/10.1111/j.1439-0450.2004.00781.x 